\title{
A deaf-mute with Huntington's chorea
}

\author{
E. M. R. CRITCHLEY AND R. H. SECKER-WALKER \\ From University College Hospital, London
}

Huntington's chorea was said to have originated from an infidel who mocked by mime Christ's agony on the Cross (Bickford and Ellison, 1953). Most descendants of this man have been spared other afflictions: the disease is horrible enough. Rosanoff (1923), Hughes (1925), Spillane and Phillips (1937), and Lyon (1962) have all commented on the rarity of any associated nervous or mental disease. Thus Rosanoff found that other conditions occurred 'relatively so infrequently as to be readily accounted for as coincidences essentially without relation to the chorea itself'.

Congenital deafness always carries the risk that the sufferer will never acquire speech and will consequently be forced to sign his wants. Such people, even today, may justifiably be referred to as deafmute. That a person relying on gesture for all communication should also be afflicted with the dread chorea must appear as a singularly cruel quirk of fate.

This patient, we believe, is only the second to be reported with this association of disorders. In the earlier case report (Bonduelle, Gruner, and Bouygues, 1953) no objective reference was made to their patient's difficulty in communication.

\section{CASE REPORT}

R.P., a carpenter aged 50, was admitted to this hospital as an emergency in May 1965 . He was deaf and dumb. His history was obtained from his wife, who was also a deafmute, and interpreted by his 11-year-old daughter.

For six months he had been getting increasingly short of breath, and had had several episodes of abdominal pain and vomiting. He was constipated, but had also been incontinent of faeces. His appetite was poor.

On examination, he showed evidence of dementia and chorea, with poor attention span, frequent grimacing, and continual choreiform movements. The movements involved all four limbs (the arms being more affected than the legs), and the head and neck. He made occasional grunts but was otherwise silent.

The cranial nerves, with the exception of the eighth nerve, were normal. There was no response to loud noises in either ear. Both drums were normal.

Apart from the involuntary movements and postures, motor testing in the limbs was normal, reflexes brisk and symmetrical and plantars flexor. Sensory testing was limited but no abnormality was found.

On admission, his temperature was $99.8^{\circ} \mathrm{F}$., pulse 132 per minute, regular, and blood pressure $180 / 100$ $\mathrm{mm}$. $\mathrm{Hg}$.

The heart sounds were normal and there were no signs of heart failure. He was dyspnoeic: respiratory rate $32 / \mathrm{min}$. There was no cyanosis. The percussion note was diminished at both bases with absent breath sounds. Bowels sounds were audible at both bases.

The tongue was dry. The abdomen was markedly distended and generally tender. No organs were palpable. The abdomen was tympanitic to percussion and the bowel sounds were tinkling. Rectal examination revealed a large quantity of faecal material.

A diagnosis of Huntington's chorea was made, with dementia leading to chronic constipation, steadily increasing faecal impaction, overflow incontinence, dilatation of the large and small bowel, elevated diaphragm and hence dyspnoea.

Investigations showed haemoglobin $98 \%(14.5 \mathrm{~g} . \%)$, white blood count $9,300 /$ c.mm., E.S.R. $48 \mathrm{~mm}$. at one hour. Urine microscopy was normal. The plasma urea level was $34 \mathrm{mg} . \%$. Plasma electrolytes: total $\mathrm{CO}_{2}$ capacity $29.5 \mathrm{mEq}$./1., chloride $93 \mathrm{mEq} . / \mathrm{l}$., sodium 133 mEq./l., potassium $4.4 \mathrm{mEq} . / 1$.

Total serum proteins were 6.0 g. $\%$ (albumin 2.8 g. $\%$, globulin 3.2 g. $\%$ ).

Serum flocculation tests showed colloidal red very weakly positive, cephalin cholesterol weakly positive, and thymol turbidity 2 units. Plasma glutamic oxaloacetic transaminase was $16 \mathrm{Karmen}$ units/min./ml., and plasma alkaline phosphatase 20.3 King-Armstrong units.

A chest radiograph showed that both hemidiaphragms were elevated, but no focal lung lesion was seen. Abdominal radiographs showed gross faecal retention in the descending colon and rectum, and considerable distension of the rest of the large bowel and also of the small bowel.

An electroencephalogram, following the administration of $100 \mathrm{mg}$. each of butobarbitone and quinalbarbitone and $2 \mathrm{~g}$. of chloral, showed that there was a considerable amount of low-voltage fast activity with bursts of mostly frontal, but occasionally occipitally distributed, activity at between 12 and $14 \mathrm{c} / \mathrm{s}$. These were symmetrical. Some were undoubtedly sleep spindles, but others represented a basic activity just above the alpha range. Only a little generalized intermediate slow activity of very low voltage was seen. Considerable agitation masked the responses 


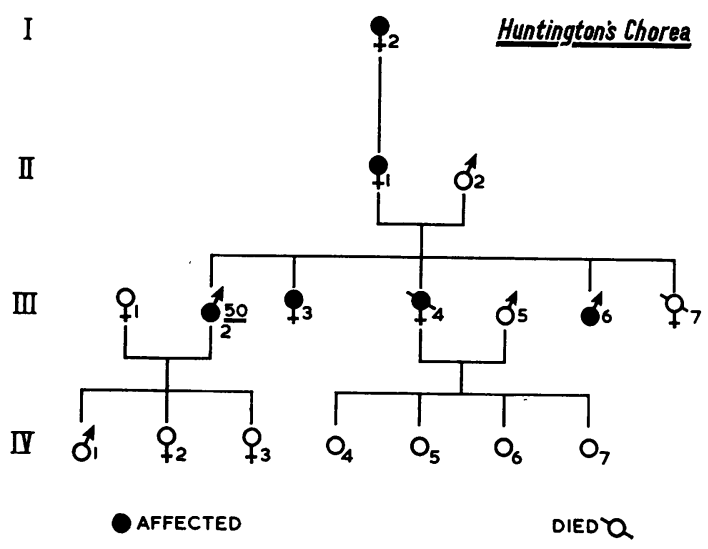

FIG. 1. Pedigree of the patient.

to photic stimulation. This was a normal record for the patient's age.

He was treated initially by gastric aspiration, enemata and laxatives, and slowly improved. As the abdominal distension subsided the dyspnoea was relieved.

From his family we learned that he had been deaf since birth. There was no history of birth trauma or of neonatal jaundice. None of his ancestors, nor any of his descendants are deaf, although his wife is a deaf-mute and has a family history of this condition.

He had always been rather simple minded and was never taught to speak. His finger spelling has always been poor.

His abnormal movements started 10 to 15 years ago, after he moved from Pontypridd in Glamorgan to London. In 1958 he was involved in a car accident, and was admitted to this hospital with a fractured femur, which was treated with an intramedullary nail. A few jerky movements were noted at this time, but he was able to leave hospital walking well on crutches after five weeks.

He was able to continue working until about five years ago, but then chorea began to interfere with his carpentry. In the last three years his family have found it increasingly difficult to understand his signs, as his choreic movements have become more bizarre and he has become demented. They comment that he is now short tempered, humourless and child-like, and unable to apply himself for more than a few seconds at a time.

From our own observations he could read simple sentences, and understand finger-spelling. However, his attention could only be held for about a minute. His writing rapidly became illegible, and it was usually only possible to distinguish the first three or four letters of a word. Likewise with his finger-spelling, there was great difficulty in deciphering letters after more than four or five.

He is the eldest of five siblings. In his son's words 'all the family get these movements when they start working too hard'. The youngest sibling died from heart disease at an early age. All the others have chorea and one of them is in a mental institution. His mother died, aged 50, in a mental institution after three years of choreiform movements; and his maternal grandmother was also affected.

Little is known of the earlier members of the family, and despite the help of Dr. J. D. Spillane and Dr. C. E. C. Wells in Glamorgan, we have been unable to trace these early sufferers.

\section{DISCUSSION}

The cause of this patient's deafness has not been determined. In two recent surveys of hereditary deafness (Fisch, 1964; Fraser, 1964) no mention is made of any relationship between Huntington's chorea and deafness, nor had either of these authors encountered such a case in the course of their experience of deafness (personal communications).

Worster-Drought and Allen in 1929 described a deaf and dumb child of a choreic father but did not follow her for sufficiently long to exclude chorea. Minski and Guttmann in 1938 in a survey of Huntington's chorea note in family 27 of their series 'several cases of deafness not coinciding with the chorea'. In the absence of further elaboration it may be assumed that these were of adult, acquired deafness. In 1953 Bonduelle et al., in reporting two siblings with Huntington's chorea and spasmodic paraplegia, mention that they had difficulty communicating with the second patient as she had been deaf and dumb since early infancy. The cause of her deafness had not been determined and no other member of the family suffered from deafness.

Several methods of communication may be used? by profoundly deaf people. That of speech and speech-reading (lip-reading) is preferred often to the exclusion of all other means of communication by schools for the deaf. It may be augmented in all except a few who possess hardly any residual hearing by the use of hearing aids (the aural method), and is most successful in those with a high I.Q., who begin speech-training early and have a reasonable degree of residual hearing. One stage lower in the hierarchy of deaf-communication is finger-spelling. This is done by the bimanual method in this country and by the unimanual method in France and the U.S.A. Historically it antedated speech training and experts may achieve considerable speed and grammatical accuracy by this method. It has been claimed (Payne, 1918) that experts in finger-spelling are more literate than those taught by either the oral or the later aural method. Good finger-spellers are often of high I.Q. who have been neglected till late and have never acquired facility in lip-reading. The use of conventional signs is often frowned upon by good finger-spellers, good speakers, and most teachers of the deaf. But combined methods are 
preferred by the majority of deaf people for signs decrease the strain of unbroken finger-spelling or lip-reading and add colour to their conversation. Sign-language is ungrammatical and has yet to be systematized. It may be, as in this patient, the sole means of communication of those with low intelligence. Confusion of meanings may frequently arise and pass uncorrected and, particularly among the unintelligent, lack of clarity in signing may hamper communication.

Defects in finger-spelling due to cortical lesions, amounting to a dysphasia for this method of communication, have been noted in the past and various explanations proposed: apraxia and agnosia for dactylography (Critchley, 1938), finger agnosia (Grasset's patient, 1896), and affective disturbances (Tureen, Smolik, and Tritt, 1951). This patient demonstrates another cause for signing defects. His involuntary movements have come on gradually, and, although his spelling and literary ability have always been poor, his family have been able to adapt to the increasing paucity of communication resulting from the interference of the involuntary movements. Only in the past three years have they come to experience real difficulty. It may be surmised that in a hearing choreic patient of similar intelligence dysarthria would have hampered conversation at an even earlier stage. In fact, the chief drawback to communication in this patient has not been the interruption of signing by the involuntary movements but the limitation of his attention span and instability of mood which have resulted from his dementia.

\section{SUMMARY}

The association of Huntington's chorea and deafmutism has most probably occurred by chance.
The patient, who has always been somewhat simple-minded and has never been able to master any means of communication other than signing, crude finger-spelling, and elementary reading and writing, was nonetheless still able to be intelligible to his family in the early stages of the chorea. His recent breakdown in communication is almost certainly the result of increasing dementia and not due to the severity of his involuntary movements.

We wish to thank Dr. E. J. Ross for permission to publish this report of a patient under his care, and Dr. Ross and Dr. G. M. Stern for their help and advice in the preparation of this paper.

\section{REFERENCES}

Bickford, J .A. R., and Ellison, R. M. (1953). The high incidence of Huntington's chorea in the Duchy of Cornwall. J. ment. Sci., 99, $291-294$.

Bonduelle, M., Gruner, J., and Bouygues, P. (1953). Choróe de Huntington avec paraplégie spasmodique, Deux cas familiaux, étude anatomique. Remarque sur les relations de la surdité et des lésions de l'olive supérieure. Rev. neurol., 88, 126-131.

Critchley, M. (1938). "Aphasia" in a partial deaf-mute. Brain, 61, 163-169.

Fisch, L. (1964). Editor of Research in Deafness in Children. Blackwell, Oxford.

Fraser, G. R. (1964). Profound childhood deafness. J. med. Genet., $1,118-151$.

Grasset, J. (1896). Aphasie de la main droite chez un sourd-muet. Progr. méd. (Paris), 3 ser., 4, 281.

Hughes, E. M. (1925). Social significance of Huntington's chorea. Amer. J. Psychiat., 4, 537-574.

Lyon, R. L. (1962). Huntington's chorea in the Moray Firth area. Brit. med. J., 1, 1301-1306.

Minski, L., and Guttmann, E. (1938). Huntington's chorea: a study of 34 families. J. ment. Sci., 84, $21-96$.

Payne, A. H. (1918). King Silence. Jarrolds, London.

Rosanoff, A. J. (1923). Inheritance of Mental Disorders. In Second int. Congr. Eugenics, New York, 1921, Vol. 1: Eugenics, Genetics and the Family. p. 226.

Spillane, J., and Phillips, R. (1937). Huntington's chorea in South Wales. Quart. J. Med. n.s. 6, 403-423.

Tureen, L. T., Smolik, E. A., and Tritt, J. H. (1951). Aphasia in a deaf mute. Neurology (Minneap.), 1, 237-244.

Worster-Drought, C., and Allen, I. M. (1929). Huntington chorea; with report of two cases. Brit. med. J., 2, 1149-1152. 